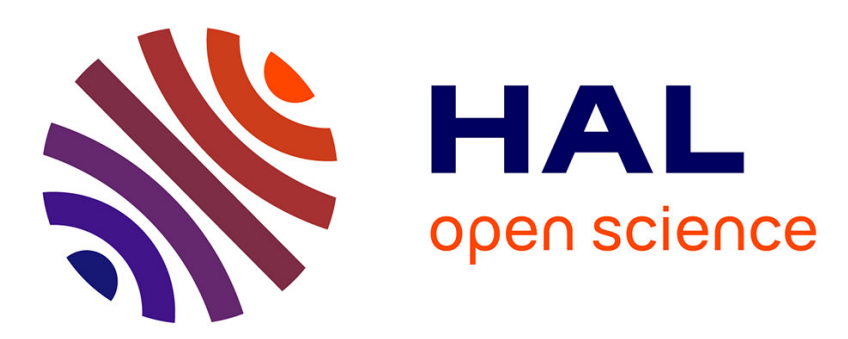

\title{
Microwave survey of the conformational landscape exhibited by the propeller molecule triethyl amine
}

Ha Vinh Lam Nguyen, Raphaela Kannengiesser, Wolfgang Stahl

\section{To cite this version:}

Ha Vinh Lam Nguyen, Raphaela Kannengiesser, Wolfgang Stahl. Microwave survey of the conformational landscape exhibited by the propeller molecule triethyl amine. Physical Chemistry Chemical Physics, 2012, 14 (33), pp.11753. 10.1039/C2CP41385J . hal-03183168

\section{HAL Id: hal-03183168 \\ https://hal.science/hal-03183168}

Submitted on 27 Mar 2021

HAL is a multi-disciplinary open access archive for the deposit and dissemination of scientific research documents, whether they are published or not. The documents may come from teaching and research institutions in France or abroad, or from public or private research centers.
L'archive ouverte pluridisciplinaire HAL, est destinée au dépôt et à la diffusion de documents scientifiques de niveau recherche, publiés ou non, émanant des établissements d'enseignement et de recherche français ou étrangers, des laboratoires publics ou privés. 


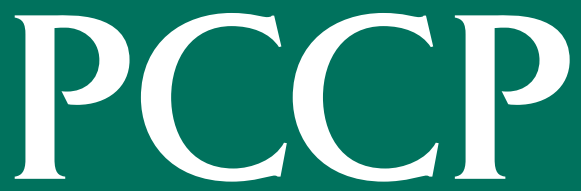

\section{Accepted Manuscript}

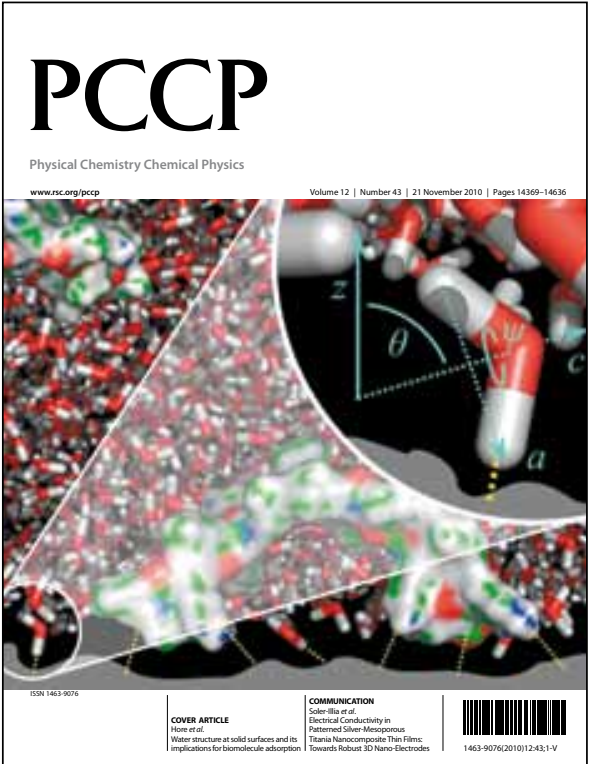

This is an Accepted Manuscript, which has been through the RSC Publishing peer review process and has been accepted for publication.

Accepted Manuscripts are published online shortly after acceptance, which is prior to technical editing, formatting and proof reading. This free service from RSC Publishing allows authors to make their results available to the community, in citable form, before publication of the edited article. This Accepted Manuscript will be replaced by the edited and formatted Advance Article as soon as this is available.

To cite this manuscript please use its permanent Digital Object Identifier $\left(\left.\mathrm{DO}\right|^{\circledast}\right)$, which is identical for all formats of publication.

More information about Accepted Manuscripts can be found in the

\section{Information for Authors.}

Please note that technical editing may introduce minor changes to the text and/or graphics contained in the manuscript submitted by the author(s) which may alter content, and that the standard Terms \& Conditions and the ethical guidelines that apply to the journal are still applicable. In no event shall the RSC be held responsible for any errors or omissions in these Accepted Manuscript manuscripts or any consequences arising from the use of any information contained in them. 


\title{
Microwave survey of the conformational landscape exhibited by the propeller molecule triethyl amine
}

\author{
Ha Vinh Lam Nguyen,* Raphaela Kannengießer, and Wolfgang Stahl ${ }^{a}$ \\ Received (in $X X X, X X X)$ Xth $X X X X X X X X X 20 X X$, Accepted $X$ th $X X X X X X X X X 20 X X$ \\ ${ }_{5}$ DOI: $10.1039 / \mathbf{b 0 0 0 0 0 0 x}$
}

Conformational studies with quantum chemical methods yielded for the most stable conformer of triethyl amine a propeller-like structure belonging to the point group $\mathrm{C}_{3}$, which corresponds to an oblate top. The microwave spectrum of this conformer with ${ }^{14} \mathrm{~N}$ hyperfine splitting of all rotational transitions was assigned and molecular parameters were determined. The rotational constants were found to be $A=B=2.314873978(11) \mathrm{GHz}$, the ${ }^{14} \mathrm{~N}$ quadrupole coupling constant $\chi_{c c}=-5.2444(07) \mathrm{MHz}$. The observed spectrum could be 10 reproduced within experimental accuracy. The standard deviation of a global fit with 43 rotational transitions is $1.5 \mathrm{kHz}$. The propellerlike structure seems to be energetic favorable and therefore also typical for related systems like triethyl phosphine, triisopropyl amine, trin-propyl amine, and tri-tert-butyl amine. Furthermore, the rotational transitions of two isotopologues, ${ }^{13} \mathrm{C}_{2}$ and ${ }^{13} \mathrm{C}_{5}$, could be measured in natural abundance and fitted with an excellent standard deviation. The $C$ rotational constants could be determined to be 1.32681(96) $\mathrm{GHz}$ and $1.32989(18) \mathrm{GHz}$ for the ${ }^{13} \mathrm{C}_{2}$ and ${ }^{13} \mathrm{C}_{5}$ isotopologues, respectively.

15

\section{Introduction}

Amines are important derivates of ammonia, where one or more protons are replaced by organic substituents. Small aliphatic amines are often used in the pharmaceutical and fertilizer 20 industry, or as solvents. Many studies on ammonia ${ }^{1}$ and its derivates have been carried out in the microwave region. In our investigation on diethyl amine, ${ }^{2}$ where two protons in ammonia are substituted by ethyl groups, three different effects influenced the spectrum. The quadrupole hyperfine splittings due to the ${ }_{25}$ nuclear spin of $I=1$ of the ${ }^{14} \mathrm{~N}$ nucleus and the splittings due to the internal rotation of the two equivalent methyl groups could be resolved. The barrier to internal rotation has been determined to be $1051 \mathrm{~cm}^{-1}$. This motivated us to study triethyl amine, a related molecule, where all the protons in ammonia are substituted by 30 ethyl groups. We were interested in comparing the ${ }^{14} \mathrm{~N}$ quadrupole coupling constants of this molecule with ammonia, diethyl amine, and other molecules like trimethyl amine, ${ }^{3}$ quinuclidine, ${ }^{4}$ and nitrogen trifluoride. ${ }^{5}$ It is also interesting to find out whether the barrier to internal rotation changes, i.e. 35 whether splittings of three internal rotors can be observed.

By rotating the ethyl groups, a large number of different geometries of triethyl amine can be generated. To find out which of those geometries are stable conformers, which conformers can be observed under molecular beam conditions, and which 40 symmetry the most stable conformer has, a combination of molecular beam Fourier transform microwave (MB-FTMW) spectroscopy and quantum chemical calculations were carried out. Furthermore, we were interested in a comparative quantum chemical study of related molecules such as triethyl phosphine, 45 triisopropyl amine, tri-n-propyl amine, and tri-tert-butyl amine.

\section{Experimental setup}

All spectra were recorded using a MB-FTMW spectrometer which is a modified version of the spectrometer described in ref. ${ }^{6}$ and ${ }^{7}$. Transitions within the frequency range from 4 to $26.5 \mathrm{GHz}$ 50 can be recorded. Triethyl amine was obtained from Merck
Schuchardt, Hohenbrunn, Germany. A mixture of triethyl amine with helium at a concentration of $1 \%$ by volume and a total pressure of $100 \mathrm{kPa}$ was used throughout.

The spectrometer can be used both in the high resolution mode 55 and in the scan mode. In the scan mode overlapping spectra in a grid of $0.25 \mathrm{MHz}$ were recorded to give the broadband scans where only the line positions are indicated. In the high resolution mode, all lines split into doublets due to the Doppler effect. All lines were rather strong. For most transitions we found a line 60 width in the range from 20 to $25 \mathrm{kHz}$. This enabled us to determine transition frequencies with an accuracy of approximately $2 \mathrm{kHz}$.

\section{Quantum chemical calculations}

\subsection{Triethyl amine}

\section{${ }_{65}$ 3.1.1 Optimization}

Triethyl amine is a molecule with 22 atoms, which is too large for a classical structure determination by isotopic substitution. Quite a big number of geometries is possible, but not all of them are stable conformers. Quantum chemistry is a helpful method for 70 calculating the conformers as well as for giving reasonable starting values of rotational constants to assign the microwave spectrum.

In total, 216 different starting geometries were calculated using the program Gaussian09 ${ }^{8}$ by varying the three dihedral 75 angles $\alpha_{1}=\angle\left(\mathrm{C}_{16}, \mathrm{~N}, \mathrm{C}_{2}, \mathrm{C}_{5}\right), \alpha_{2}=\angle\left(\mathrm{C}_{16}, \mathrm{~N}, \mathrm{C}_{9}, \mathrm{C}_{12}\right)$, and $\alpha_{3}=\angle\left(\mathrm{C}_{9}, \mathrm{~N}, \mathrm{C}_{16}, \mathrm{C}_{19}\right)$, in each case from $-120^{\circ}$ to $180^{\circ}$ in a grid of $60^{\circ}$. Atom numbers are given in Figure 1. The MP2 method and the basis set $6-311++\mathrm{G}(\mathrm{d}, \mathrm{p})$ were used, since it turned out to be reliable in many other molecules studied before..$^{9-11}$

$80 \quad$ From 216 starting geometries, only 8 conformers were found. The frequency calculation for conformer VIII yielded an imaginary frequency, i.e. this conformer is a saddle point. All other conformers are stable; they are indicated in Figure 2 in order of their relative energies. Their energy values, dipole 


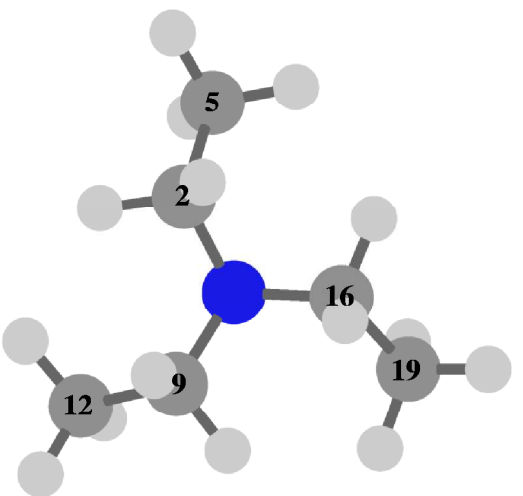

Fig. 1 Geometry of the observed conformer (most stable) of triethyl amine. Only $\mathrm{C}$ atoms are labeled.

moments, and rotational constants are given in Table 1. The 5 nuclear coordinates in the principal axes system of 7 stable conformers are available as supplementary material in Table S-1. It should be noted that conformers I, II, III, and VII each have an enantiomeric partner, whereas conformers IV and $\mathrm{V}$ have a structure with no possible enantiomeric partner.

Table 1. The energy values, dipole moments, and rotational constants of 7 stable conformers of triethyl amine.

\begin{tabular}{crcccccc}
\hline \multirow{2}{*}{ Conf. } & $\begin{array}{c}\text { rel. E } \\
\mathrm{kJ} / \mathrm{mol}\end{array}$ & $\begin{array}{c}\mu_{\mathrm{a}} \\
/ \mathrm{D}\end{array}$ & $\begin{array}{c}\mu_{\mathrm{b}} \\
/ \mathrm{D}\end{array}$ & $\begin{array}{c}\mu_{\mathrm{c}} \\
/ \mathrm{D}\end{array}$ & $\begin{array}{c}\mathrm{A} \\
/ \mathrm{GHz}\end{array}$ & $\begin{array}{c}\mathrm{B} \\
/ \mathrm{GHz}\end{array}$ & $\begin{array}{c}\mathrm{C} \\
/ \mathrm{GHz}\end{array}$ \\
\hline $\mathrm{I}$ & 11.6310 & 0.330 & 0.264 & 0.577 & 3.044 & 2.010 & 1.519 \\
$\mathrm{II}$ & 3.0817 & 0.261 & 0.367 & 0.650 & 2.931 & 2.016 & 1.373 \\
$\mathrm{III}$ & 0.0000 & 0.000 & 0.000 & 0.781 & 2.319 & 2.319 & 1.326 \\
$\mathrm{IV}$ & 2.2143 & 0.000 & 0.416 & 0.643 & 3.387 & 1.855 & 1.407 \\
$\mathrm{~V}$ & 3.2028 & 0.000 & 0.303 & 0.739 & 3.114 & 1.941 & 1.348 \\
VI & 8.2523 & 0.560 & 0.109 & 0.655 & 2.956 & 1.993 & 1.364 \\
VII & 22.5982 & 0.000 & 0.000 & 0.488 & 2.405 & 2.405 & 1.754
\end{tabular}

Conformer III is the most stable one with a $\mathrm{C}_{3}$ symmetric, propeller-like structure (see also Figure 1). The methyl groups are all tilted in the direction of the free electron pair on the nitrogen 15 atom by the same angle $\angle\left(\mathrm{C}_{5}, \mathrm{C}_{2}, \mathrm{~N}\right)=\angle\left(\mathrm{C}_{19}, \mathrm{C}_{16}, \mathrm{~N}\right)=\angle\left(\mathrm{C}_{12}\right.$, $\left.\mathrm{C}_{9}, \mathrm{~N}\right)$ of $112.5^{\circ}$. The $A$ and $B$ rotational constants are identical and a dipole moment exists only in the $c$ direction. Triethyl amine is consequently an oblate top. Conformer VII is likewise an oblate top. In this case, the methyl groups are tilted away from 20 the free electron pair. However, this conformer has an energy

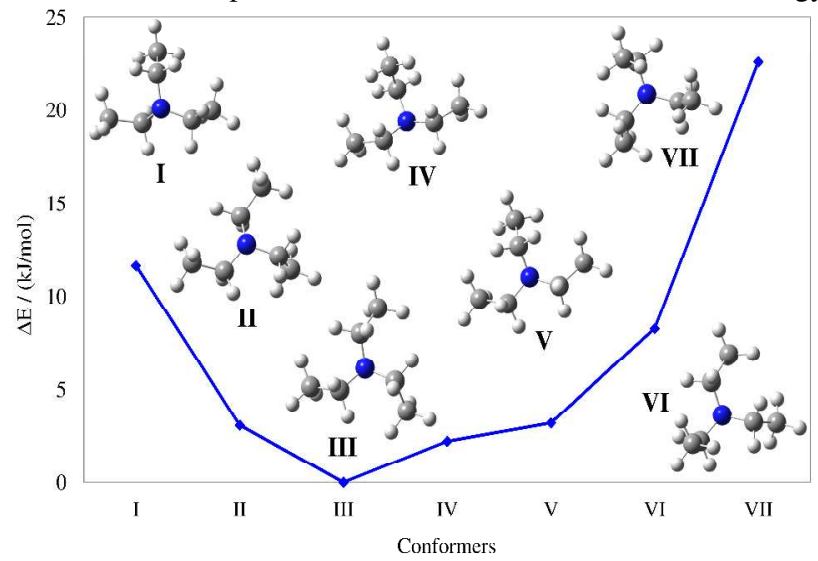

Fig. 2 Stable conformers of triethyl amine calculated at the MP2/6$311++\mathrm{G}(\mathrm{d}, \mathrm{p})$ level. The energy values are relative to the most stable conformer III ( -291.559737 Hartree). Only one enantiomer of conformers $25 \mathrm{I}$, II, III and VII is indicated.

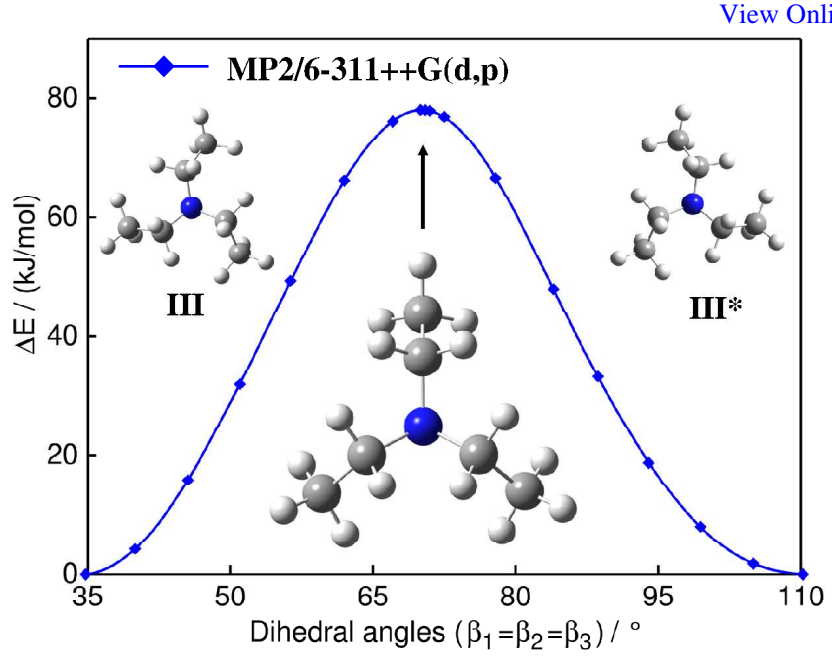

Fig. 3 The potential energy curve obtained by varying the dihedral angles $\beta_{1}=\angle\left(\mathrm{C}_{2}, \mathrm{~N}, \mathrm{C}_{19}, \mathrm{C}_{16}\right), \beta_{2}=\angle\left(\mathrm{C}_{9}, \mathrm{~N}, \mathrm{C}_{5}, \mathrm{C}_{2}\right)$, and $\beta_{3}=\angle\left(\mathrm{C}_{16}, \mathrm{~N}, \mathrm{C}_{12}, \mathrm{C}_{9}\right)$ and keeping the dihedral angle $\beta_{4}=\angle\left(\mathrm{C}_{5}, \mathrm{C}_{12}, \mathrm{C}_{19}, \mathrm{~N}\right)$ fixed.

30 value $22.6 \mathrm{~kJ} / \mathrm{mol}$ higher than that of conformer III and is unlikely to be observed under molecular beam conditions.

As mentioned before, the most stable conformer III appears as an enantiomeric pair. The propeller-like structure can have a clockwise or anti-clockwise direction. To find out, whether a 35 tunneling process between the two enantiomers is possible, calculations to determine the transition state were carried out. Three dihedral angles $\beta_{1}=\angle\left(\mathrm{C}_{2}, \mathrm{~N}, \mathrm{C}_{19}, \mathrm{C}_{16}\right), \beta_{2}=\angle\left(\mathrm{C}_{9}, \mathrm{~N}, \mathrm{C}_{5}\right.$, $\left.\mathrm{C}_{2}\right)$, and $\beta_{3}=\angle\left(\mathrm{C}_{16}, \mathrm{~N}, \mathrm{C}_{12}, \mathrm{C}_{9}\right)$, which are all $34.77^{\circ}$ and $110.24^{\circ}$ in conformer III and its enantiomer III*, respectively, were kept 40 fixed whereas other molecular parameters were allowed to relax. Assuming that these angles vary continuously in the same way, $\beta_{1}, \beta_{2}$, and $\beta_{3}$ were varied from $34.77^{\circ}$ to $110.24^{\circ}$ in a grid of $10.78^{\circ}$. In addition, a further dihedral angle $\beta_{4}=\angle\left(\mathrm{C}_{5}, \mathrm{C}_{12}, \mathrm{C}_{19}\right.$, $\mathrm{N})$ has to be fixed at $17.84^{\circ}$ in all calculations to keep the 45 distance between the nitrogen atom and the $\mathrm{C}_{5}-\mathrm{C}_{12}-\mathrm{C}_{19}$ plane constant. This value was found in both conformer III and III*. The energy curve is given in Figure 3. Some additional calculations were carried out to have a better parameterization. The Fourier coefficients are available as supplementary material 50 (Table S-2). The energy maximum is expected to be at about $70.5^{\circ}$.

We assumed that the transition state should have an exact $\mathrm{C}_{3 \mathrm{v}}$ structure since the three ethyl groups are equivalent. Taking this constraint, we created a $\mathrm{C}_{3 \mathrm{v}}$ starting geometry by rotating one of 55 the ethyl groups of the structure at the maximum $\left(\beta_{1}=\beta_{2}=\beta_{3}=70.5^{\circ}\right)$ by $120^{\circ}$ and $240^{\circ}$. A full optimization of this $\mathrm{C}_{3 \mathrm{v}}$ starting geometry to a minimum retained the $\mathrm{C}_{3 \mathrm{v}}$ structure indicated in Figure 4. A frequency calculation showed three imaginary frequencies, which correspond to the deformation of ${ }_{60}$ the three ethyl groups from conformer III to conformer III*. The tunneling barrier between the two enantiomers is approximately

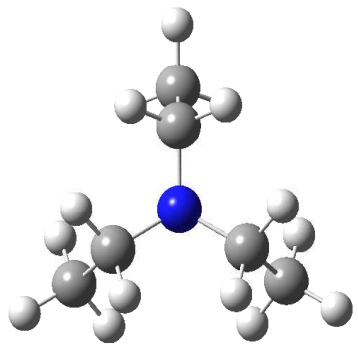

Fig. 4 Geometry of the transition state of triethyl amine with a $\mathrm{C}_{3 \mathrm{v}}$ symmetry. 
Table 2. Parameters describing the overall rotation and ${ }^{14} \mathrm{~N}$ quadrupole coupling of triethyl amine as well as its ${ }^{13} \mathrm{C}_{2}$ and ${ }^{13} \mathrm{C}_{5}$ isotopologues filtew Online the program spfit.

\begin{tabular}{llllll}
\hline Parameter & Unit & Main isotopologue & Calc. & ${ }^{13} \mathrm{C}_{2}$ isotopologue & ${ }^{13} \mathrm{C}_{5}$ isotopologue \\
\hline$A$ & $\mathrm{GHz}$ & $2.314873978(11)^{\mathrm{a}}$ & $2.3194^{\mathrm{b}}$ & $2.31293315(34)$ & $2.31302815(28)$ \\
$B$ & $\mathrm{GHz}$ & $2.314873978(11)$ & $2.3191^{\mathrm{b}}$ & $2.29283301(33)$ & $2.25126785(40)$ \\
$C$ & $\mathrm{GHz}$ & 1.3262 (fixed) & $1.3262^{\mathrm{b}}$ & $1.32681(96)$ & $1.32989(18)$ \\
$D_{J}$ & $\mathrm{kHz}$ & $0.9619(17)$ & & $0.9694(88)$ & $1.369(14)$ \\
$D_{J K}$ & $\mathrm{kHz}$ & $-1.5885(43)$ & & $-3.594(27)$ & $1.988(25)$ \\
$\chi_{\mathrm{cc}}$ & $\mathrm{MHz}$ & $-5.2444(07)$ & $-5.2425^{\mathrm{c}}$ & $-5.2660(40)$ & $-5.947(98)$ \\
$\chi_{\mathrm{bb}}-\chi_{\mathrm{aa}}$ & $\mathrm{MHz}$ & $0.0^{\mathrm{d}}$ & & & $-0.257(19)$ \\
$\mathrm{N}$ & & 43 & & 16 & 10 \\
$\sigma$ & $\mathrm{kHz}$ & 1.5 & & 0.5 & 0.4 \\
\hline
\end{tabular}

${ }^{a}$ Parameters are given with one standard uncertainty in parentheses.

${ }^{\mathrm{b}}$ Calculated at the MP2/6-311++G(d,p) level.

${ }^{\mathrm{c}}$ Structure optimization at the MP2/6-311+G(df,pd) level, electric field gradient calculation at the B3PW91/6-311+G(d,p) level (see text).

${ }^{\mathrm{d}}$ Due to symmetry.

$27 \mathrm{~kJ} / \mathrm{mol}$. Due to the high barrier, we conclude that a splitting due to an enantiomer tunneling process cannot be observed under molecular beam conditions. It should be noted that the energy of the transition state is much lower than the energy of about 80 $5 \mathrm{~kJ} / \mathrm{mol}$ found for the maximum at $70.5^{\circ}$, since the structures are different, as indicated in Figure S-1 in supplementary material. The Cartesian coordinates of the transition state are given in Table S-3.

\subsection{Related molecules}

\section{3.2.1 Triethyl phosphine}

Analogous to triethyl amine, three dihedral angles $\alpha_{1}=\angle\left(\mathrm{C}_{16}\right.$, $\left.\mathrm{P}, \mathrm{C}_{2}, \mathrm{C}_{5}\right), \alpha_{2}=\angle\left(\mathrm{C}_{16}, \mathrm{P}, \mathrm{C}_{9}, \mathrm{C}_{12}\right)$, and $\alpha_{3}=\angle\left(\mathrm{C}_{9}, \mathrm{P}, \mathrm{C}_{16}, \mathrm{C}_{19}\right)$ were defined. In this case, 8 starting geometries were calculated, which were based on the structure of the triethyl amine 15 conformers. From these starting geometries, 7 conformers were found. One of them is a saddle point, all others should exist as stable conformers. The most stable conformer of triethyl phosphine (indicated in Figure 5) has the known propeller-like structure and is consequently an oblate top. However, the ethyl 20 groups are not tilted in the direction of the free electron pair, but are located almost in a plane containing the phosphorous atom.

\subsubsection{Triisopropyl amine, tri-n-propyl amine, and tri-tert-} butyl amine

In the case of triisopropyl amine, the $\mathrm{H}_{3}, \mathrm{H}_{5}$, and $\mathrm{H}_{7}$ atoms can 25 be considered as the methyl groups $\mathrm{C}_{5}, \mathrm{C}_{12}$, and $\mathrm{C}_{19}$ of triethyl amine, respectively. On the other hands, the methyl groups can be seen as the protons. Therefore, the dihedral angles were chosen to be $\alpha_{1}=\angle\left(\mathrm{C}_{6}, \mathrm{~N}, \mathrm{C}_{2}, \mathrm{H}_{3}\right), \alpha_{2}=\angle\left(\mathrm{C}_{6}, \mathrm{~N}, \mathrm{C}_{4}, \mathrm{H}_{5}\right)$, and $\alpha_{3}=\angle\left(\mathrm{C}_{4}\right.$,
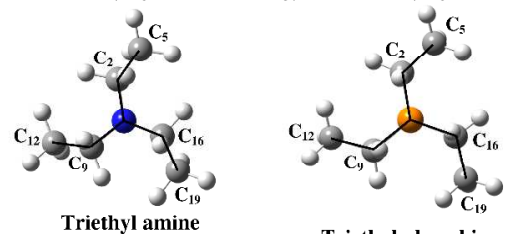

Triethyl phosphine

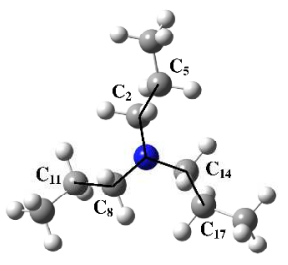

Tri-n-propyl amine - chain

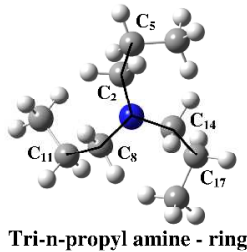

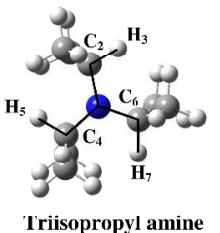

I'riisopropyl amine

Tri-tert-butyl amine

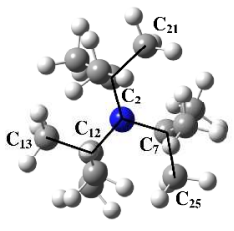

30 Fig. 5 The propeller-like structure found in triethyl amine and related molecules
$\mathrm{N}, \mathrm{C}_{6}, \mathrm{H}_{7}$ ) in order to enable a direct comparison with the conformers of triethyl amine. After optimizations, 8 conformers were found and 7 of them represent true minima. Once again, a 35 propeller-like structure was found for the most stable conformer. In the case of tri-n-propyl amine, many starting geometries are possible due to the long alkyl chains. Therefore, we began only with the starting geometries based on the most stable conformer III of triethyl amine. Two conformers were found, one with a 40 zigzag chain structure, the other with a ring structure. The propeller-like structure is conserved in both cases.

For tri-tert-butyl amines, only one conformer could be found, once again with the propeller-like structure, and existing as an enantiomeric pair. For comparison, the most stable conformers of 45 all molecules are shown in Figure 5. It should be noted that all of them are oblate tops. The energy values, dipole moments, and rotational constants of all conformers, as well as the Cartesian coordinates of the most stable conformers are given in the supplementary material in Table S-4.

\section{${ }_{50}$ 4. Microwave spectrum}

\subsection{Main isotopologue}

Conformer III of triethyl amine is most stable. Therefore, it is expected to be observed under molecular beam conditions, where the rotational temperature is often very low, approximately $2 \mathrm{~K}$.

${ }_{55}$ The rotational energy levels can be calculated using the rotational constants from quantum chemical results. Using the spectrometer described in ref. ${ }^{6,7}$, small scans of about $20 \mathrm{MHz}$ around the predicted frequency of the transitions $J=2 \leftarrow 1$ and $J=3 \leftarrow 2$ were recorded. Approximately $5 \mathrm{MHz}$ broad multiplets were ${ }_{60}$ found due to the hyperfine quadrupole splittings of the ${ }^{14} \mathrm{~N}$ nucleus. These frequency ranges were remeasured in the high resolution mode in a grid of $0.25 \mathrm{MHz}$. A typical spectrum is shown in Figure 6, the complete scan of the $J=3 \leftarrow 2$ transition in Figure 7. At the beginning, 10 lines of the $J=2 \leftarrow 1$ and 12 65 lines of the $J=3 \leftarrow 2$ transition were found and fitted with the program spfit/spcat written by Pickett. ${ }^{12}$ A more accurate theoretical spectrum could be predicted with the fitted parameters. Further lines of the transitions $J=4 \leftarrow 3$ and $J=5 \leftarrow 4$ could be measured directly in the high resolution 70 mode. In total, 48 lines were found, assigned, and fitted. The fitted molecular parameters are given in Table 2, a list of ten $J=2 \leftarrow 1$ transitions in Table 3 . The complete data set as well as the parameter definition (*.par) file of the program spfit can be found in supplementary material (Table S-5 and S-6). 


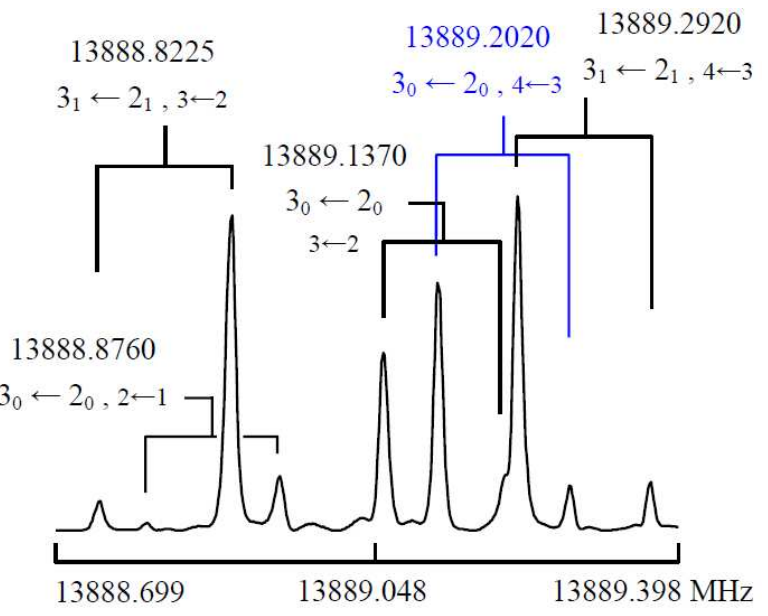

Fig. 6 A typical spectrum of the $3_{K} \leftarrow 2_{K}, F \leftarrow F$ transition of triethyl amine measured in the high resolution mode. Doppler splittings are marked by brackets. For this spectrum, 601 FID were co-added.

Table 3. Observed frequencies ( $v_{\text {Obs. }}$ ) of ten $J=2 \leftarrow 1$ transitions of the main isotopologue of triethyl amine. $v_{\text {Calc. }}$ is the calculated value; $v_{\text {Obs. }}-v_{\text {Calc. }}$ are values obtained after a fit with the program spfit. $J$ and $K_{c}$ are the symmetric top rotational quantum numbers, $F$ is the total angular momentum in the coupled basis with $\boldsymbol{F}=\boldsymbol{J}+\boldsymbol{I}$.

\begin{tabular}{|c|c|c|c|c|c|c|c|}
\hline \multicolumn{3}{|c|}{ Upper level } & \multicolumn{3}{|c|}{ Lower level } & \multirow{2}{*}{$\begin{array}{l}v_{\text {Obs. }} \\
\mathrm{MHz}\end{array}$} & \multirow{2}{*}{$\begin{array}{c}v_{\text {Obs. }}-v_{\text {Calc. }} \\
\mathrm{kHz}\end{array}$} \\
\hline$J$ & $K_{c}$ & $F$ & $J$ & $K_{c}$ & $F$ & & \\
\hline 2 & 0 & 3 & 1 & 0 & 2 & 9259.5790 & 1.5 \\
\hline 2 & 0 & 2 & 1 & 0 & 1 & 9259.4630 & -2.1 \\
\hline 2 & 0 & 2 & 1 & 0 & 2 & 9257.8925 & 0.5 \\
\hline 2 & 0 & 1 & 1 & 0 & 1 & 9262.0870 & -0.6 \\
\hline 2 & 0 & 1 & 1 & 0 & 2 & 9260.5150 & 0.6 \\
\hline 2 & 1 & 1 & 1 & 1 & 0 & 9261.4380 & -0.6 \\
\hline 2 & 1 & 2 & 1 & 1 & 1 & 9258.1610 & 0.2 \\
\hline 2 & 1 & 3 & 1 & 1 & 2 & 9259.7895 & -0.5 \\
\hline 2 & 1 & 2 & 1 & 1 & 2 & 9258.9470 & -0.2 \\
\hline 2 & 1 & 1 & 1 & 1 & 2 & 9260.2590 & 0.3 \\
\hline
\end{tabular}

\section{2 ${ }^{13} \mathrm{C}$ isotopologue}

In addition to the rotational spectrum of the main ${ }^{12} \mathrm{C}$ isotopologue, several lines of ${ }^{13} \mathrm{C}$ isotopologues could be ${ }_{10}$ observed. With 6 carbon atoms, many ${ }^{13} \mathrm{C}$ isotopologues are available; however, some of them are equivalent. They are the isotopologues with ${ }^{13} \mathrm{C}$ substituent at the $\mathrm{C}_{2}, \mathrm{C}_{9}$, and $\mathrm{C}_{16}$ positions and at the $\mathrm{C}_{5}, \mathrm{C}_{12}$, and $\mathrm{C}_{19}$ positions. In both cases, the frequency of occurrence increases from approximately $1.1 \%$ to $3.3 \%$.

15 Therefore, it is possible to measure these isotopologues in their natural concentrations.

The Cartesian coordinates of conformer III obtained from the program Gaussian09 were transformed to principal axes coordinates. The mass of the substituted ${ }^{12} \mathrm{C}$ atom was changed to ${ }_{20}$ that of the ${ }^{13} \mathrm{C}$ atom. The rotational constants were calculated and used as starting values to predict the theoretical spectrum with the program spcat. ${ }^{12}$ All lines were measured directly in the high resolution mode. In total, 16 transitions of the ${ }^{13} \mathrm{C}_{2^{-}}$and 10 transitions of the ${ }^{13} \mathrm{C}_{5}$ isotopologue were assigned and fitted. It 25 should be noted that the molecule becomes asymmetric due to the ${ }^{13} \mathrm{C}$ substituent and is no longer an oblate top. Therefore, the $C$ rotational constants could be determined. All fitted transitions are listed in Table S-7 and S-8 in the supplementary material. The molecular parameters can be found also in Table 2 with the main

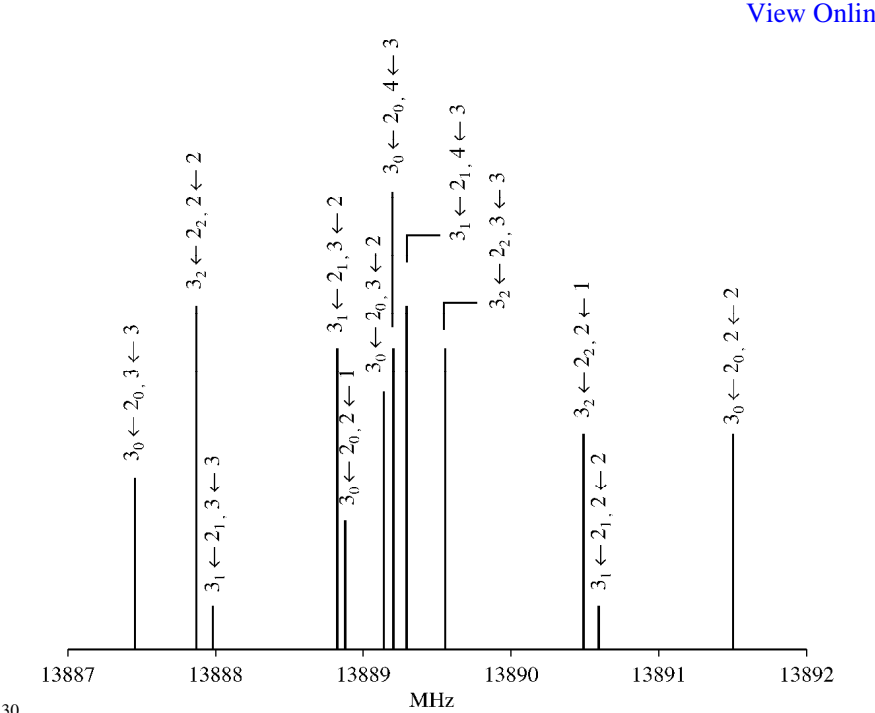

Fig. 7 The complete scan of the $3_{K} \leftarrow 2_{K}, F \leftarrow F$ transition of triethyl amine measured in the high resolution mode in a grid of $0.25 \mathrm{MHz}$. The intensity is estimated.

35 isotopologue. The parameter definition (*.par) files of the program spfit are also given in Table S-5.

\section{Results and discussion}

The structure of triethyl amine obtained by microwave spectroscopy has some interesting aspects. Even though this 40 molecule is relatively large with 22 atoms, its most stable conformer is an oblate top. It has the propeller structure and is thereby chiral. The triethyl amine propeller can have a clockwise or anti-clockwise direction, depending on the respective enantiomer.

45 The rotational transitions of the main isotopologue are located within several small frequency ranges and could be found easily in the spectrum. All recorded lines were assigned and fitted with a standard deviation of $1.5 \mathrm{kHz}$, within the experimental accuracy. The $A$ and $B$ rotational constants calculated on the ${ }_{50} \mathrm{MP} 2 / 6-311++\mathrm{G}(\mathrm{d}, \mathrm{p})$ level were reasonable starting values. The absolute deviation was only $4 \mathrm{MHz}(0.2 \%)$. Determination of the $C$ rotational constant is not possible for this oblate top.

Calculations of the quadrupole coupling constants for diethyl amine at the MP2/6-311++G(d,p) level yielded the $\chi_{\text {aa }}$ value with 55 a deviation of $3.4 \%$. For the $\chi_{b b}-\chi_{c c}$ and the $\chi_{b c}$ value, the deviations are considerably larger $(11 \%$ in both cases $) .^{2}$ Electric field gradient calculations of Bailey on this molecule ${ }^{13}$ at the B3PW91/6-311+G(d,p) level of theory based on the optimized structure at the MP2/6-311+G(df,pd) level using the correction ${ }_{60}$ factor $\mathrm{eQ} / \mathrm{h}$ of $4.5617(43)$ MHz/a.u. ${ }^{14}$ could calculate the coupling constants almost exactly to the experimental values. Therefore, we assumed that optimizations with the MP2 method yield quite reasonable molecular structure parameters. However, for electric field gradient the density functional theory turned out 65 to be much more suitable. A combination of both methods was also used in this case to calculate the quadrupole coupling constant $\chi_{z z}$. The structure was optimized using different methods and basis sets. Afterwards, point calculation of the electric field gradient was carried out with the B3PW91/6-311+G(d,p) level. 70 The results are given in Table 4. Also in this case, the structure optimized at the MP2/6-311+G(df,pd) level of theory yielded the best result which has almost perfect agreement with the experimental value with a deviation of $0.03 \%$. 
Table 4. The $\chi_{\mathrm{zz}}$ quadrupole coupling constant (in $\mathrm{MHz}$ ) of ${ }^{14} \mathrm{~N}$ in triethyl amine. The electric field gradient was calculated at the B3PW91/6$311+G(d, p)$ level whereas the structure was optimized with a different method and basis set.

\begin{tabular}{ll}
\hline Basis set & $\chi_{z z}$ \\
\hline B3PW91/6-311+G(d,p) & -5.4585 \\
MP2/6-311+G(d,p) & -5.2566 \\
MP2/6-311++G(d,p) & -5.3498 \\
MP2/6-311+G(df,pd) & -5.2461 \\
MP2/6-311+G(3df,3pd) & -5.3011 \\
\hline
\end{tabular}

The symmetric top character of triethyl amine allows a direct comparison of the $\chi_{z z}$ quadrupole coupling constant with other symmetric top molecules like nitrogen trifluoride, ammonia, 5 trimethyl amine, and quinuclidine (see Table 5). The $\chi_{z z}$ value of triethyl amine is determined to be $-5.2444 \mathrm{MHz}$, almost the same as the value of $-5.1915 \mathrm{MHz}$ found for quinuclidine. ${ }^{4}$ The corresponding value of $-5.47 \mathrm{MHz}$ reported for trimethyl amine $\mathrm{s}^{3}$ is slightly higher. It is interesting to compare this value with 10 values for ammonia ${ }^{1}$ and nitrogen trifluoride $\mathrm{NF}_{3},{ }^{5}$ which are $-4.0842 \mathrm{MHz}$ and $-7.903 \mathrm{MHz}$, respectively. The value for ammonia is much lower and the one for nitrogen trifluoride much higher. This effect might be due to the different inductive effects of these substituents. In the case of triethyl amine and 15 quinuclidine, the substituents are carbon chains, whereas only methyl groups exist in trimethyl amine. However, all of these alkyl substituents have a positive inductive effect. In the case of ammonia, the protons have no inductive effect. For nitrogen trifluoride, the negative inductive effect of the fluorine atoms 20 might have influence on the quadrupole constant.

Table 5. The $\chi_{z z}$ quadrupole coupling constant (in $\mathrm{MHz}$ ) of ${ }^{14} \mathrm{~N}$ in triethyl amine. The electric field gradient was calculated at the B3PW91/6 $311+\mathrm{G}(\mathrm{d}, \mathrm{p})$ level whereas the structure was optimized with a different method and basis set.

\begin{tabular}{ll}
\hline & $\chi_{z z}{ }^{a}$ \\
\hline nitrogen trifluoride $^{5}$ & -7.903 \\
ammonia $^{1}$ & -4.0842 \\
triethyl amine & -5.2444 \\
quinuclidine $^{4}$ & -5.1915 \\
trimethyl amine $^{3}$ & -5.47 \\
\hline${ }^{\mathrm{a}} \chi_{\mathrm{xx}}=\chi_{\mathrm{yy}}=-0.5 \chi_{\mathrm{zz}}$ &
\end{tabular}

25

The rotational transitions of the ${ }^{13} \mathrm{C}$ isotopologues could be fitted with an excellent standard deviation of lower than $0.5 \mathrm{kHz}$ in both cases. The $A$ rotational constant is almost the same as the one of the main isotopologue, however, the $B$ constants are 30 appreciably lower. The difference is $22.1 \mathrm{MHz}$ and $63.6 \mathrm{MHz}$ for the ${ }^{13} \mathrm{C}_{2}$ and the ${ }^{13} \mathrm{C}_{5}$ isotopologue, respectively. Unlike the ${ }^{12} \mathrm{C}$ isotopologue, the $\mathrm{C}$ rotational constant could be determined and has almost exactly the value calculated at the MP2/6$311++\mathrm{G}(\mathrm{d}, \mathrm{p})$ level of theory.

${ }_{35}$ Using Kraitchman's molecular structure determination, ${ }^{15}$ the projections of the $\mathrm{C}_{2}$ - and $\mathrm{C}_{5}$-atoms on the $\mathrm{C}_{3}$ symmetry axes can be determined. For the $\mathrm{C}_{2}$ atom, $\mid \mathrm{yl}=1.38774(86) \AA$ and $|\mathrm{z}|=0.4269(28) \AA$ were found. For the $\mathrm{C}_{5}$ atoms, the respective values are $|y|=2.45489(49) \AA$ and $|z|=0.4267(28) \AA$. The 40 standard deviation is determined using equation (5.38) in ref. ${ }^{16}$. It should be noted that the $|z|$ values for the $C_{2}$ and $C_{5}$ atoms are identical. However, the optimized structure calculated at the MP2/6-311++G(d,p) level has shown that one of the $z$ values is positive and the other one is negative, i.e. the plane through the 45 center of mass and vertical to the $\mathrm{C}_{3}$ axes is exactly in the middle of the $\mathrm{C}_{2}$ and $\mathrm{C}_{5}$ atoms. The determined values are very close to the calculated ones of $(|y|,|z|)=(1.3918 \AA, 0.4269 \AA)$ and
$(2.4557 \AA, 0.4267 \AA)$ for the $\mathrm{C}_{2}$ and $\mathrm{C}_{5}$ atoms, respectively. Unfortunately, the $\mathrm{C}_{2}-\mathrm{C}_{5}$ bond length could not be determined 50 since information on the ${ }^{15} \mathrm{~N}$ isotopologue is missing. No lines of the ${ }^{15} \mathrm{~N}$ isotopologue can be observed because the ${ }^{15} \mathrm{~N}$ transitions are located almost at the same position where the strong ${ }^{14} \mathrm{~N}$ transitions also exist.

Finally, it should be mentioned that no additional splittings 55 were found in the spectrum. This means that the splittings due to internal rotation of the three methyl groups are very small and cannot be resolved even in the high resolution mode. The reason might be a somewhat higher barrier than that we observed in diethyl amine or a more complex spectrum caused by three 60 internal rotors where many unresolved torsional components overlap resulting in broadened lines.

\section{Conclusions}

The propeller-like structure of triethyl amine with two possible enantiomers was found by a combination of microwave ${ }_{65}$ spectroscopy and quantum chemistry. The rotational constants could be determined within the experimental accuracy of $1.5 \mathrm{kHz}$ using the program spfit/spcat written by Pickett. The structure was confirmed by the results obtained from two isotopologues measured in their nature abundances using Kraitchman's 70 equation. Theoretical calculations on the transition state and some related molecules were carried out. Furthermore, the $\chi_{\mathrm{zz}}$ quadrupole coupling constant could be calculated exactly to the experimental value using Bailey's method reported in ref. ${ }^{14}$. A direct comparison with some other symmetric top molecules 75 supports that the inductive effect might influent this parameter.

\section{Acknowledgements}

We thank the Center for Computing and Communication of the RWTH Aachen University for free computer time and the Land Nordrhein-Westfalen for funds. Furthermore, we thank H. M. ${ }_{80}$ Pickett for making his code available to the spectroscopic community.

\section{Notes and references}

a Institute of Physical Chemistry, RWTH Aachen University, Landoltweg 2, 52074 Aachen, Germany. Fax: +49 24180 92365; Tel: 85 +4924180 94759; E-mail: nguyen@pc.rwth-aachen.de

$\dagger$ Electronic Supplementary Information (ESI) available. See DOI: 10.1039/b000000x/

1 G. R. Gunther-Mohr, R. L. White, A. L. Schawlow, W. E. Good, D. K. Coles, Phys. Rev., 1954, 94, 1184.

902 H. V. L. Nguyen, W. Stahl, J. Chem. Phys., 2011, 135, 024310.

3 J. E. Wollrab and V. W. Laurie, J. Chem. Phys., 1969, 51, 1580.

4 D. Consalvo and W. Stahl, J. Mol. Struct., 1998, 447, 119.

5 S. E. Novick, W. Chen, M. R. Munrow, K. J. Grant, J. Mol. Spectrosc., 1996, 179, 219.

956 U. Andresen, H. Dreizler, J.-U. Grabow, W. Stahl, Rev. Sci. Instrum., 1990, 61, 3694.

7 J.-U. Grabow, W. Stahl, H. Dreizler, Rev. Sci. Instrum., 1996, 67, 4072.

8 Gaussian 09, Revision A.02, M. J. Frisch, G. W. Trucks, H. B. 100 Schlegel, G. E. Scuseria, M. A. Robb, J. R. Cheeseman, G. Scalmani, V. Barone, B. Mennucci, G. A. Petersson, H. Nakatsuji, M. Caricato, X. Li, H. P. Hratchian, A. F. Izmaylov, J. Bloino, G. Zheng, J. L. Sonnenberg, M. Hada, M. Ehara, K. Toyota, R. Fukuda, J. Hasegawa, M. Ishida, T. Nakajima, Y. Honda, O. Kitao, H. Nakai, T. Vreven, J. 105 A. Montgomery, Jr., J. E. Peralta, F. Ogliaro, M. Bearpark, J. J. Heyd, E. Brothers, K. N. Kudin, V. N. Staroverov, R. Kobayashi, J. Normand, K. Raghavachari, A. Rendell, J. C. Burant, S. S. Iyengar, J. Tomasi, M. Cossi, N. Rega, J. M. Millam, M. Klene, J. E. Knox, J. B. Cross, V. Bakken, C. Adamo, J. Jaramillo, R. Gomperts, R. E. 
Stratmann, O. Yazyev, A. J. Austin, R. Cammi, C. Pomelli, J. W. Ochterski, R. L. Martin, K. Morokuma, V. G. Zakrzewski, G. A. Voth, P. Salvador, J. J. Dannenberg, S. Dapprich, A. D. Daniels, O. Farkas, J. B. Foresman, J. V. Ortiz, J. Cioslowski, D. J. Fox,

5 Gaussian, Inc., Wallingford CT, 2009.

9 D. Jelisavac, D. Cortés-Gómez, H. V. L. Nguyen, L. W. Sutikdja, W. Stahl, and I. Kleiner, J. Mol. Spectrosc., 2009, 257, 111.

10 H. V. L. Nguyen and W. Stahl, J. Mol. Spectrosc., 2010, 264, 120.

11 H. Mouhib, Y. Zhao, W. Stahl, J. Mol. Spectrosc., 2010, 261, 59.

1012 H. M. Pickett, J. Mol. Spectrosc., 1991, 148, 371.

13 http://web.mac.com/wcbailey/nqcc/Diethylamine.html

14 W. C. Bailey, Chem. Phys., 2000, 252, 57.

15 J. Kraitchman, Amer. J. Phys., 1953, 21, 17.

16 J. Demaison, J. E. Boggs, A. G. Császár, Equilibrium Molecular 15 Structures: From Spectroscopy to Quantum Chemistry, CRC Press, Boca Raton, FL, 2011. 


\section{Table of contents entry}

\section{Color graphic:}

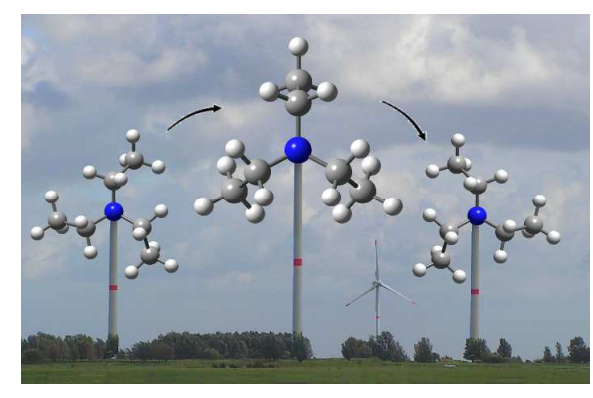

Text:

The energetically favorable structure of triethyl amine has a chiral propeller form with a $\mathrm{C}_{3 \mathrm{v}}$ symmetry transition state. 